\title{
Pleural effusion during bromocriptine exposure in two patients with pre-existing asbestos pleural plaques: a relationship?
}

\author{
C. Knoop*, M. Mairesse**, C. Lenclud*, P.A. Gevenois', P. De Vuyst*
}

Pleural effusion during bromocriptine exposure in two patients with pre-existing asbestos pleural plaques: a relationship? C. Knoop, M. Mairesse, C. Lenclud, P.A. Gevenois, P. De Vuyst. CERS Journals Ltd 1997.

ABSTRACT: Two patients with pleural plaques developed pleural effusion and subsequent diffuse pleural fibrosis 50 and 39 yrs after their first exposure to asbestos. The diagnosis of benign asbestos pleural effusion was suggested, but the work-up finally suggested bromocriptine-induced pleural disease in both patients.

These two cases illustrate that drug-induced pleural effusion is an important differential diagnosis of benign asbestos pleural effusion. It is, moreover, possible that pre-existing asbestos pleural lesions, or even asbestos exposure, increases the risk of developing bromocriptine-induced pleural disease.

Eur Respir J 1997; 10: 2898-2901.
Depts of *Chest Medicine and +Radiology, Erasme Hospital, Brussels, Belgium. **Dept of Chest Medicine, Clinique Saint-Luc, Bouge, Belgium.

Correspondence: C. Knoop, Dept of Chest Medicine, Erasme Hospital, 808 Route de Lennik, 1070 Brussels, Belgium.

Keywords: Benign asbestos pleural effusion, bromocriptine, drug-induced pleural effusion, ergoline, ergot-derived dopamine agonists, Parkinson's disease

Received: January 131997

Accepted after revision June 1997
An ever increasing number of drugs are implicated in causing pleural effusions. However, the diagnosis of drug-induced pleural effusion remains difficult to establish as there are no biological markers or specific pathological features. Similarly, the diagnosis of benign asbestos pleural effusion in exposed workers remains a challenge, because it is based on the history of exposure and on the exclusion of all other causes of pleural effusion [1]. We report the case of two patients with pre-existing asbestos pleural lesions, who presented with sterile pleural exudates, 50 and $39 \mathrm{yrs}$ after their first exposure to asbestos, and in whom work-up suggested drug-induced pleural disease due to bromocriptine treatment of Parkinson's disease.

\section{Case 1}

A 64 yr old man presented with progressively worsening dyspnoea and a weight loss of $8 \mathrm{~kg}$ over a period of 2 months. He had never smoked. From 1946 until 1956 and from 1969 until 1984, he had been employed in a railway factory, where he had been exposed to asbestos used as an insulation material. Exposure had been particularly intense between 1946 and 1954 .

In 1992, a routine chest radiograph revealed bilateral pleural plaques (fig. 1), which were confirmed by computed tomography (CT). Lung function tests, including the carbon monoxide transfer coefficient $(K \mathrm{CO})$ were normal at that time. Asbestos bodies were not detected in a bronchoalveolar lavage (BAL). Parkinson's disease was diagnosed in the early 1990 s, and was initially treated with levodopa. In order to avoid late dyskinesia, levodopa was replaced by bromocriptine, $10 \mathrm{mg}$ t.i.d.,

For editorial comment see page 2695

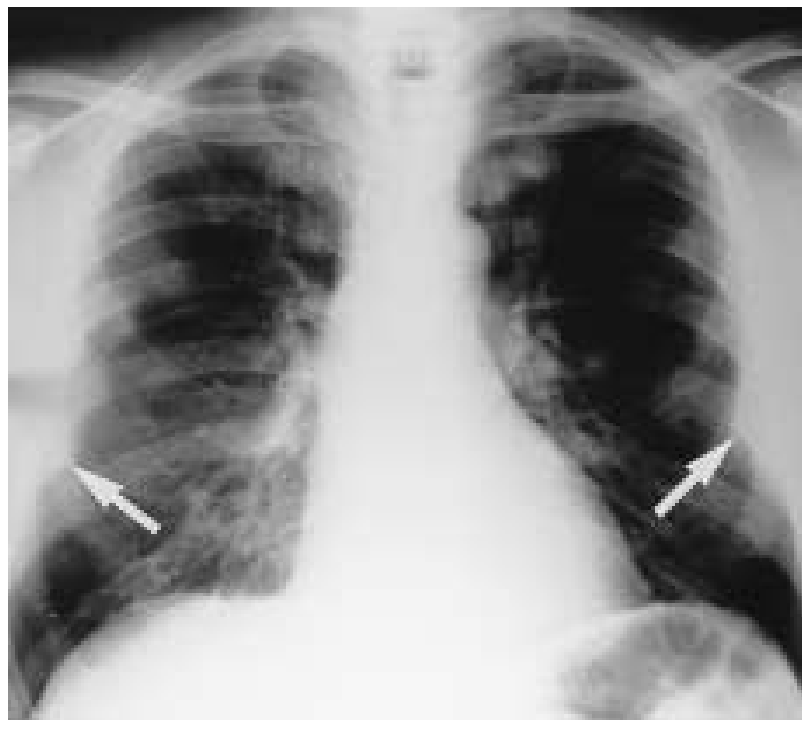

Fig. 1. - Three years before admission, the chest radiograph of patient No. 1 shows bilateral pleural plaques (arrows).

associated with selegiline from September 1993 onwards.

At the time of admission, in December 1994, asbestos exposure had ceased 10 yrs earlier, and physical examination was unremarkable, except for decreased breath sounds in both lung bases. A chest radiograph showed bilateral diffuse pleural thickening, and a large rightsided pleural effusion (fig. 2). A CT scan performed after thoracocentesis confirmed the presence of diffuse pleural fibrosis associated with a rounded atelectasis, and multiple parenchymal bands (fig. 3). Lung function tests revealed a severe restrictive ventilatory defect with a total lung capacity (TLC) of $4.3 \mathrm{~L}$ (67\% of predicted), 


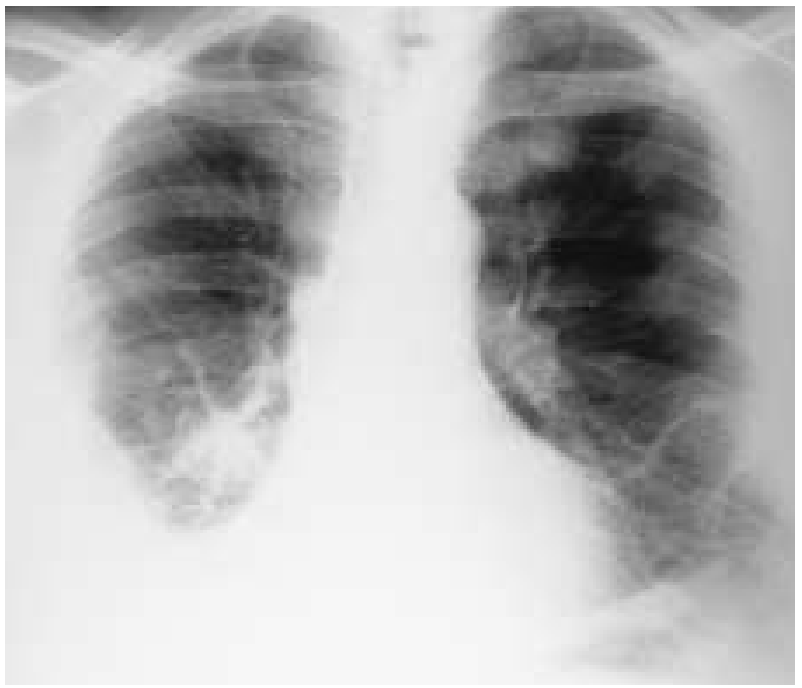

Fig. 2. - At the time of admission, the chest radiograph of patient No. 1 shows a right-sided pleural effusion.

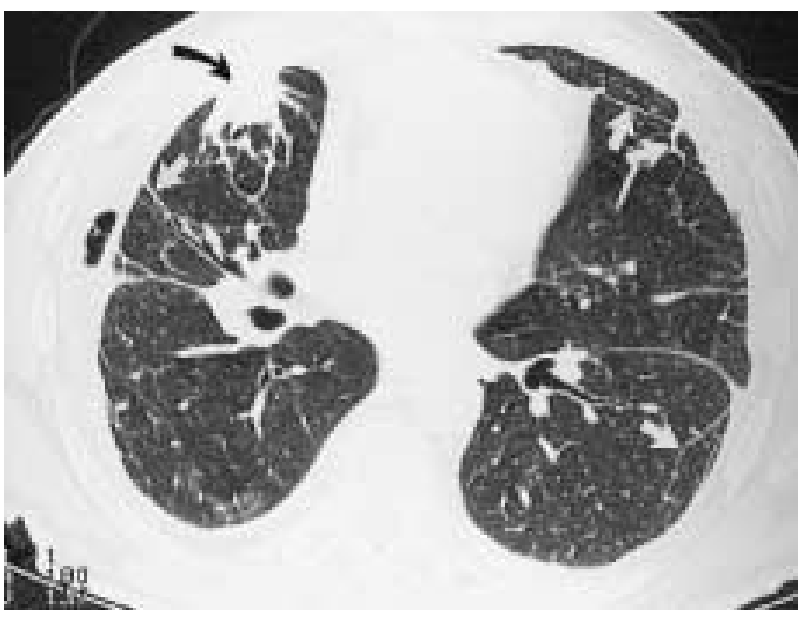

Fig. 3. - Thoracic computed tomography (CT) scan in patient No. 1 shows bilateral pleural thickening associated with parenchymal bands (white arrows) and rounded atelectasis (black arrow).

a vital capacity (VC) of $1.8 \mathrm{~L}$ (47\% pred), forced expiratory volume in one second (FEV1) of $1.6 \mathrm{~L}(54 \%$ pred), and a normal $K \mathrm{CO}$. BAL showed no bacteria and no asbestos bodies. Thoracocentesis yielded a strawcoloured sterile lymphocytic exudate. No malignant cells were detected. An attempt at thoracoscopy failed because of symphysis of the parietal and visceral pleura. Random pleural biopsies taken with an Abram's needle showed marked fibrosis. The erythrocyte sedimentation rate (ESR) was $64 \mathrm{~mm} \cdot \mathrm{h}^{-1}$ (normal value $1-10 \mathrm{~mm} \cdot \mathrm{h}^{-1}$ ), the C-reactive protein (CRP) concentration was $4 \mathrm{mg} \cdot 100$ $\mathrm{mL}^{-1}$ (normal value $<1 \mathrm{mg} \cdot 100 \mathrm{~mL}^{-1}$ ) and there was mild normochrome, normocytic anaemia with $11.5 \mathrm{~g} \cdot 100 \mathrm{~mL}^{-1}$ haemoglobin (normal value $13-17.7 \mathrm{~g} \cdot 100 \mathrm{~mL}^{-1}$ ). A test for antinuclear antibodies and rheumatoid factor were negative. A tuberculin skin test was negative. A cardiac ultrasound was normal.

A diagnosis of benign asbestos pleural effusion was suggested, but the diagnosis of bromocriptine-induced pleural disease was favoured. The cumulative dose of bromocriptine at this time-point was $13.5 \mathrm{~g}$. Accordingly, bromocriptine was tailed-off and, because of the systemic illness and the severe restrictive ventilatory pat- tern, prednisolone was administered at a daily dose of $1 \mathrm{mg} \cdot \mathrm{kg}^{-1}$. Within 1 month, the patient's symptoms and lung function improved. After 4 months, steroids were progressively tapered. Twelve months after the initial presentation, lung function tests were normal: TLC 5.7 L (89\% pred), VC $3.2 \mathrm{~L}$ (86\% pred), FEV1 $2.3 \mathrm{~L}$ (81\% pred); but the chest radiograph still showed pleural thickening and blunting of both costophrenic angles. Pleural fibrosis diminished over time on follow-up CT scans.

\section{Case 2}

A 58 yr old man presented with dyspnoea, fatigue, anorexia and weight loss over a period of 5 weeks. He had been a cigarillo smoker for several years, but had stopped smoking 7 yrs before admission. He had worked as a tiler-plasterer for $36 \mathrm{yrs}$, and had been exposed to asbestos fibres between 1950 and 1965. Since 1981, he had suffered from Parkinson's disease treated with bromocriptine at a dose of $10 \mathrm{mg}$, once a day, between 1986 and 1988 followed by a dose of $7.5 \mathrm{mg}$, three times daily since April 1988.

At the time of admission in June 1989, the physical examination was unremarkable except for diminished breath sounds in both lung bases. A chest radiograph revealed right-sided pleural effusion, blunting of the left costodiaphragmatic angle, and lamellar atelectasis at the left lung base. A CT scan showed multiple rounded atelectases, and pleural calcifications. Lung function tests showed a severe restrictive ventilatory pattern: TLC 6.5 L (61\% pred), VC 2.6 L (55\% pred), FEV1 1.9 L (56\% pred), with a normal $K \mathrm{CO}$. Thoracocentesis yielded a sterile eosinophilic exudate $(60 \%)$. No malignant cells were detected. The BAL was negative for usual and acid-fast bacteria, but yielded 5 asbestos bodies $\cdot \mathrm{mL}^{-1}$ (normal value $<1$ asbestos body $\cdot \mathrm{mL}^{-1}$ ). There was a raised ESR of $107 \mathrm{~mm} \cdot \mathrm{h}^{-1}$ (normal value $<9 \mathrm{~mm} \cdot \mathrm{h}^{-1}$ ), CRP concentration of $9.1 \mathrm{mg} \cdot 100 \mathrm{~mL}^{-1}$ (normal value $<1.2 \mathrm{mg} \cdot 100$ $\left.\mathrm{mL}^{-1}\right)$, and a moderate peripheral eosinophilia, 670 cells $\cdot \mathrm{mm}^{-3}$ (normal value $<440$ cells $\cdot \mathrm{mm}^{-3}$ ), was present. A tuberculin skin test was negative.

Because of the history of occupational exposure to asbestos and the presence of pleural calcifications, a diagnosis of benign asbestos pleural effusion was initially suggested, and no treatment was given. During the following year, the patient persistently complained of fatigue and lost a further $4 \mathrm{~kg}$ in weight. The ESR remained elevated, whereas thoracic findings remained unchanged. In December 1990, he was readmitted with the possibility of a drug-induced pleural reaction, and thus bromocriptine was stopped. The cumulative dose of bromocriptine treatment at this time-point was $26.4 \mathrm{~g}$. Remarkably, the patient's general symptoms abated quickly, and the inflammatory syndrome disappeared within the ensuing month. Neither the chest radiograph nor lung function tests have improved substantially.

\section{Discussion}

Occupational or environmental exposure to asbestos fibres may cause various pleural manifestations, including pleural plaques, pleural effusion, diffuse pleural 
fibrosis and malignant mesothelioma [2]. These conditions may occur separately or in combination, are sometimes associated with parenchymal disease. Benign asbestos pleural effusion occurs in about $5 \%$ of asbestosexposed individuals [3, 4]. Asbestos effusions are most often unilateral. Remarkably, more than half of the patients remain asymptomatic. Pleural fluid is often a haemorrhagic, lymphocytic exudate, but occasional pleural eosinophilia has been reported [4]. The diagnosis is based on a history of asbestos exposure, and the exclusion of all other causes of pleural effusion. Spontaneous resolution within a few months is common, but in many patients diffuse pleural thickening persists [5].

Patient No. 1 had first been exposed to asbestos almost 50 yrs before the onset of the acute episode, exposure ceased 10 yrs before admission, and calcified pleural plaques were diagnosed 3 yrs before admission. In this patient, the diagnosis of benign asbestos pleural effusion was raised, but the association of pleural disease and a systemic illness contrasted sharply with a quiescent period of $50 \mathrm{yrs}$. CT findings [6] and pleural biopsies were against a diagnosis of malignant mesothelioma. The occurrence of pleural changes 15 months after initiation of bromocriptine treatment, the acute systemic illness, and the prompt resolution after discontinuation of the drug all suggest that bromocriptine was the cause in this case. In patient No. 2, the first exposure to asbestos occurred 40 yrs before the acute illness, but pleural lesions had not been detected before admission. It is, however, likely that the patient had pre-existing asbestosrelated lesions, since pleural calcifications were already present. Because of the obvious history of occupational exposure, the presence of pleural fibrosis and rounded atelectases, a diagnosis of asbestos pleural disease was made, the effusion was considered as benign asbestos pleural effusion and the drug history was initially overlooked. Because of continuing symptoms, the patient was re-evaluated 18 months later, i.e. 5 yrs after the initiation of bromocriptine treatment, and bromocriptine then was stopped with prompt resolution of the systemic illness, which indicates that bromocriptine was also the probable cause in this case.

Bromocriptine is structurally similar to methysergide, which is well known to cause retroperitoneal and pleural fibrosis [7]. Since the initial publication by RiNNE [8] in 1981, there have been several reports suggesting a possible relationship between ergot derivatives (either ergotamine, bromocriptine, or the novel generation of long-acting dopamine agonists, cabergoline, nicergoline and lisuride) and pleural disease [9-12]. For review see [13]. The mechanism, by which ergot derivatives induce pleural damage is unknown. Ergot derivative-induced pleural disease is characterized by dyspnoea and often thoracic pain, and is frequently associated with a systemic illness, including fatigue, fever and weight loss, as well as an acute inflammatory syndrome, raised ESR and anaemia. Its occurrence may be dose-related. As for benign asbestos pleural effusion, there are no clearcut diagnostic features. Lymphocytic or eosinophilic exudative effusions have been observed, sometimes associated with pleural fibrosis. Classically, pulmonary involvement is limited to rounded atelectasis and fibrous strands, so-called crow's feet, which reflect an encasement of the underlying lung. In some instances, however, neutrophilic or lymphocytic alveolitis has been observed [9, 12], and recently two definite cases of interstitial pneumonitis due to dihydroergocristine have been described [13]. Apart from pleural calcifications, which are lacking in ergot-induced pleurisy, ergot-induced pleural lesions are indistinguishable from those induced by asbestos [13]. Treatment consists of withdrawal of the offending drug, and improvement of systemic features thereafter is the best diagnostic test. The outcome is most often favourable, but complete recovery seems to be rare [7, 10, 13]. It has to be stressed that pleural disease may progress and cause serious illness if the condition remains unrecognized [10].

One of the questions that these case reports raise is: do pre-existing asbestos-induced pleural lesions increase the risk of developing drug-induced pleural disease? Bromocriptine-induced pleural effusion has previously been seen in an asbestos-exposed machine operator [9] as well as in an asbestos-exposed ironer [13]. Moreover, an increased risk of ergot derivative-induced pleural disease in patients with asbestos-related disease has recently been reported by HiLlerdal et al. [14]. This suggests that patients with asbestos pleural plaques, or even asbestos exposure, but without radiologically detectable lesions, may have an increased risk of developing druginduced pleural effusions. Mechanisms of interaction between asbestos fibres and ergoline drugs are unknown, but the two agents may act in concert to elicit pleural inflammation. It is also conceivable that the presence of pleural plaques and/or asbestos fibres in the parietal pleura may block lymphatic structures involved in the drainage of pleural fluid [15].

In conclusion, although benign asbestos pleural effusion is a well-accepted clinical entity in asbestos-exposed workers, drug-induced effusion should be considered as well. A thorough work-up to determine the cause of pleural effusion in those taking ergolines is not only of academic or medicolegal interest, but also of practical therapeutic importance. Finally, although we cannot prove it, we feel that the association of asbestos- and bromocriptine-induced pleural disease in these patients was not fortuitous, but rather that patients exposed to asbestos may be at an increased risk of pleural effusions of any kind, which may relate to impaired fluid clearance from the pleural cavities.

\section{References}

1. Eisenstadt HB. Asbestos pleurisy. Dis Chest 1964; 46: 78-81.

2. Craighead JE, Abraham JE, Churg A, et al. The pathology of asbestos-associated diseases of the lungs and pleural cavities: diagnostic criteria and proposed grading schema. Arch Pathol Lab Med 1982; 106: 544-590.

3. Epler GR, McLoud TC, Gaensler EA. Prevalence and incidence of benign asbestos pleural effusion in a working population. J Am Med Assoc 1982; 247: 617-622.

4. Hillerdal G, Özesmi M. Benign asbestos pleural effusion: 73 exudates in 60 patients. Eur J Respir Dis 1987; 71: 113-121.

5. Lilis R, Lerman Y, Selikoff IJ. Symptomatic benign pleural effusion among asbestos insulation workers: residual radiographic abnormalities. Br J Ind Med 1988; 45: 443-449. 
6. Leung AN, Müller NL, Miller RR. CT in differential diagnosis of diffuse pleural disease. Am J Roentgenol 1990; 154: 487-492.

7. Graham JR, Suby HI, LeCompte PR Sadowsky NL. Fibrotic disorders associated with methysergide therapy for headache. N Engl J Med 1966; 274: 359-368.

8. Rinne UK. Pleuropulmonary changes during long-term bromocriptine treatment for Parkinson's disease. Lancet 1981; $1: 44$

9. Wiggins J, Skinner C. Bromocriptine induced pleuropulmonary fibrosis. Thorax 1986; 41: 328-330.

10. McElvaney NG, Wilcox PG, Churg A, Fleetham JA. Pleuropulmonary disease during bromocriptine treatment of Parkinson's disease. Arch Intern Med 1988; 148 : 2231-2236.

11. Bhatt MH, Keenan SP, Fleetham JA, Calne DB. Pleuro- pulmonary disease associated with dopamine agonist therapy. Ann Neurol 1991; 30: 613-616.

12. Frans E, Dom R, Demedts M. Pleuropulmonary changes during treatment of Parkinson's disease with a long-acting ergot derivative, cabergoline. Eur Respir J 1992; 5: 263-265.

13. Pfitzenmeyer P, Foucher P, Dennewald G, et al. Pleuropulmonary changes induced by ergoline drugs. Eur Respir J 1996; 9: 1013-1019.

14. Hillerdal G, Lee J, Blomkvist A, et al. Ergot alkaloids and chronic pleuropulmonary fibrosis: synergistic effects with asbestosis? (Abstract). Annual Meeting of the ACCP, San Francisco, October 1996. Chest 1996; 110: 188S.

15. Boutin C, Dumortier P, Rey F, Viallat JR, De Vuyst P. Black spots concentrate oncogenic asbestos fibers in the parietal pleura. Am J Respir Crit Care Med 1996: 153: 444-449. 